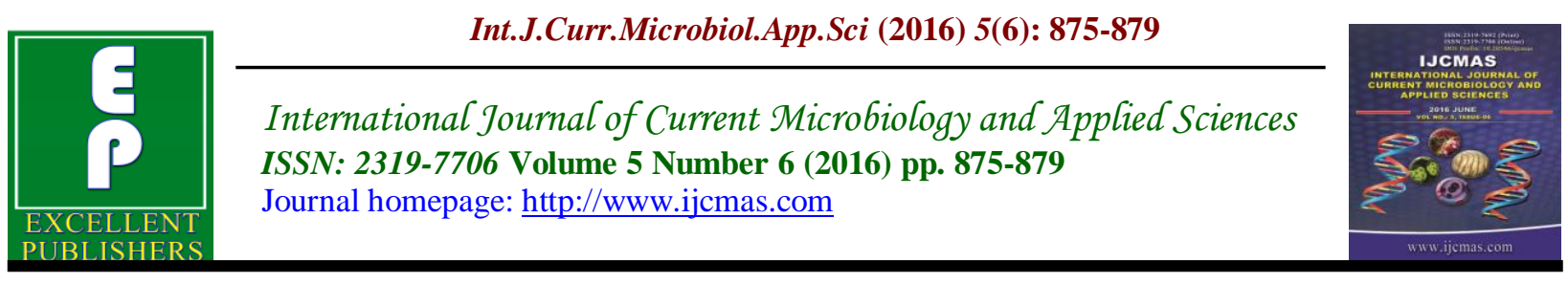

Original Research Article

http://dx.doi.org/10.20546/ijcmas.2016.506.094

\title{
Inducible Clindamycin resistance in Staphylococcus aureus isolated from Clinical Samples at C. U. Shah Medical College and Hospital, Surendranagar, Gujarat, India
}

\author{
Sanyogita Jain*, Atul Rukadikar and Anil Kumar Jain \\ Department of Microbiology, Chirayu Medical College and Hospital, Bhopal, MP, India \\ *Corresponding author
}

\begin{abstract}
A B S T R A C T
Keywords

Clindamycin,

Staphylococcus

aureus,

Clinical

Samples,

D-test

\section{Article Info}

Accepted:

28 May 2016

Available Online:

10 June 2016

Clindamycin is one of the important antibiotics for the therapy of skin and soft tissue infections caused by Staphylococcus aureus particularly MRSA (methicillinresistant $S$. aureus). In vitro routine tests for clindamycin susceptibility may fail to detect inducible clindamycin resistance due to erm genes. Use of clindamycin in such cases would result in treatment failure. D-test (Disk approximation test) is an accurate and simple test which can be used for detection of clindamycin resistance in laboratory. The present study was carried out to determine incidence of inducible clindamycin resistance among clinical isolates of $S$. aureus by D-test. The study was conducted from April 2010 to May 2015. Total108 Staphylococcus aureus strains were isolated and identified from various clinical specimens. Antibiotic susceptibility testing including detection of methicillin resistance was done by disk diffusion method as per standard guidelines. All erythromycin resistant $S$. aureus isolates were subjected to D-test to detect the inducible clindamycin resistance as per CLSI guidelines. Out of total $108 \mathrm{~S}$. aureus isolates, 50 were erythromycin resistant. Out of 50 erythromycin resistant isolates, 13 (12\%) showed inducible clindamycin resistance, $4(3.7 \%)$ showed constitutive resistance while remaining $33(30.55 \%)$ showed MS phenotype in D-test. Inducible resistance was found to be higher in MRSA (23.8\%). The incidence of inducible clindamycin resistance was $12 \%$ in present study. D-test is simple and handy test to detect inducible clindamycin resistance in $S$. aureus isolates. Clindamycin is not a suitable drug for D-test positive isolates while it can definitely prove to be a drug of choice in case of D-test negative isolates.
\end{abstract}

\section{Introduction}

Antibiotic resistance in Staphylococcus aureus has become an ever-increasing problem. In Staphylococcus, penicillin resistance was recognized first in 1944 and methicillin resistance was recognized first in 1961. ${ }^{[1]}$
Emergence of methicillin resistance in Staphylococcus aureus has left us with very few therapeutic alternatives available to treat staphylococcal infections. The macrolidelincosamide-streptogramin B $\left(\mathrm{MLS}_{\mathrm{B}}\right)$ family of antibiotics serves as one such alternative, with clindamycin being the preferred agent 
due to its excellent pharmacokinetic properties. ${ }^{[2]}$

However, widespread use of $\mathrm{MLS}_{\mathrm{B}}$ antibiotics has led to an increase in number of staphylococcal strains acquiring resistance to $\mathrm{MLS}_{\mathrm{B}}$ antibiotics. ${ }^{[3]}$ The most common mechanism for such resistance is target site modification mediated by erm genes which can be expressed either constitutively (constitutive MLS $_{\mathrm{B}}$ phenotype) or inducibely (inducible $\mathrm{MLS}_{\mathrm{B}}$ phenotype). Strains with inducible resistance to clindamycin are difficult to detect in the routine laboratory as they appear erythromycin resistant and clindamycin sensitive in vitro when not placed adjacent to each other. In such cases, in vivo therapy with clindamycin may select constitutive erm mutants leading to clinical therapeutic failure. In case of another mechanism of resistance mediated through $m s r A$ genes via efflux of antibiotic, Staphylococcal isolates appear erythromycin resistant and clindamycin sensitive both in vivo and in vitro and the strain do not typically become clindamycin resistant during therapy. ${ }^{[4]}$ The chemical structures of macrolides, lincosamides and streptogramin B are very different, but their mechanism of action is identical. All 3 antibiotics block protein synthesis by inhibiting peptidyl transferase. Bacteria develop cross resistance quite often to $\mathrm{MLS}_{\mathrm{B}}$ due to overlapping binding sites in 23S rRNA. ${ }^{[5]}$

In inducible $\mathrm{MLS}_{\mathrm{B}}$ resistance, the bacteria produce inactive mRNA which is unable to encode methylase. The mRNA becomes active only in the presence of a macrolide inducer. Bacterial strains having an inducible erm gene are resistant to the inducer but appear to be susceptible to clindamycin by the disc diffusion method, so when reported as 'Clindamycin sensitive', clinicians have only two options, either to avoid prescribing a useful drug such as clindamycin or to lead to a therapeutic failure by using it. Inducible clindamycin resistance is not detected by standard broth microdilution testing, automated susceptibility testing devices, the standard disc diffusion test or the E-test ${ }^{[6] .}$

The present study was carried out to determine the incidence of inducible clindamycin resistance among clinical isolates of Staphylococcus aureus by D-test (In accordance with CLSI Guideline).

\section{Materials and Methods}

The study was conducted from April 2010 to May 2015 at the Department of Microbiology, C.U.Shah Medical College and Hospital, Surendranagar, Gujarat. The study was approved by Institutional Ethics Committee (Human Research). A total of 108 Staphylococcus aureus were isolated from various clinical specimens like pus, wound swab, aspirates, blood and body fluids.

Antibiotic susceptibility testing was performed for all $S$. aureus strain by disk diffusion method. Detection of methicillin resistance was done by Cefoxitin $(30 \mu \mathrm{g})$ disk diffusion method. Inducible clindamycin resistance was detected by Dtest, as per CLSI guidelines on erythromycin resistant isolates. ${ }^{[]]}$

\section{Screening for inducible clindamycin resistance}

Mueller Hinton agar plate was inoculated with 0.5 McFarland bacterial suspension, erythromycin $(15 \mu \mathrm{g})$ disc was placed at a distance of $15 \mathrm{~mm}$ (edge to edge) from clindamycin $(2 \mu \mathrm{g})$ disc and after overnight incubation at $37^{0} \mathrm{C}$, zone of inhibition around clindamycin in the area between the 
two discs were observed ${ }^{[7]}$ [Figure1].

Three different phenotypes were appreciated after testing and interpreted as follows:

1. MS Phenotype: Staphylococcal isolates exhibiting resistance to erythromycin (zone size $\leq 13 \mathrm{~mm}$ ) while sensitive to clindamycin (zone size $\geq 21 \mathrm{~mm}$ ) and giving circular zone of inhibition around clindamycin [Figure 1a].

2. Inducible MLS $_{\mathrm{B}} \quad$ Phenotype: Staphylococcal isolates showing resistance to erythromycin (zone size $\leq 13 \mathrm{~mm}$ ) while being sensitive to clindamycin (zone size $\geq 21 \mathrm{~mm}$ ) and giving D shaped zone of inhibition around clindamycin with flattening towards erythromycin disc [Figure $1 \mathrm{~b}$ ].

3. Constitutive MLS в Phenotype: Staphylococcal isolates which showed resistance to both erythromycin (zone size $\leq 13 \mathrm{~mm}$ ) and clindamycin (zone size $\leq 14 \mathrm{~mm}$ ) with circular shape of zone of inhibition if any around clindamycin [Figure 1c].

\section{Results and Discussion}

$108 \mathrm{~S}$. aureus isolates isolated from clinical specimens were tested for susceptibility to erythromycin and other antibiotics including cefoxitin by disc diffusion testing. 50 $(32.4 \%)$ isolates were found to be erythromycin resistant. Erythromycin resistant isolates were subjected to D-test. Out of 50 isolates, $4(3.7 \%)$ were resistant to both erythromycin and clindamycin indicating constitutive $\mathrm{MLS}_{\mathrm{B}}$ Phenotype, 46 isolates were clindamycin sensitive. Out of 46, $13(12 \%)$ isolates showed positive D-test indicating inducible $\mathrm{MLS}_{\mathrm{B}}$ phenotype, while 33 (30.55\%) showed negative D-test indicating MS phenotype.
Out of 108 S. aureus isolates $42(\%)$ isolates were found to be cefoxitin resistant (MRSA). 27 MRSA isolates were found to be erythromycin resistant. Out of 27 MRSA isolates, $3(7.14 \%)$ isolates were constitutive $\mathrm{MLS}_{\mathrm{B}}$ Phenotype, 10 (23.80\%) isolates were inducible $\mathrm{MLS}_{\mathrm{B}}$ phenotype, while 14 $(33.33 \%)$ isolates were MS phenotype. (Table 1)

The determination of antimicrobial susceptibility of a clinical isolate is often crucial for optimal antimicrobial therapy. This is particularly important considering the increase of resistance and the emergence of multidrug resistant organisms. Clindamycin is one of the important antibiotics for the therapy of skin and soft tissue infections caused by Staphylococcus aureus particularly MRSA. ${ }^{[2]}$

However, clindamycin resistance can develop in staphylococcal isolates with inducible phenotype, and from such isolates, spontaneous constitutively resistant mutants have arisen both in vitro testing and in vivo during clindamycin therapy. [8] Reporting Staphylococcus aureus as susceptible to clindamycin without checking for inducible resistance may result in institution of inappropriate clindamycin therapy. On the other side negative result for inducible clindamycin resistance confirms clindamycin susceptibility and provides very good therapeutic option. ${ }^{[8]}$

In present study out of $108 \mathrm{~S}$. aureus isolates 50 (32.4\%) were erythromycin resistant. Amongst them $13(12 \%)$ isolates were inducible clindamycin resistant, $4(3.7 \%)$ were constitutive clindamycin resistant and 33 (30.55\%) were clindamycin sensitive (MS phenotype) as per D-test. The percentages of inducible resistance $(23.80 \%)$ and MS phenotype $(33.33 \%)$ were higher amongst MRSA. 
Table.1 Distribution of isolates-

\begin{tabular}{|l|l|l|}
\hline Susceptibility pattern & S. aureus & MRSA \\
\hline ERY-S, CL-S & $58(53.7 \%)$ & $15(35.71 \%)$ \\
\hline $\begin{array}{l}\text { Constitutive MLS в Resistance } \\
\text { (ERY-R,CL-R) }\end{array}$ & $4(3.7 \%)$ & $3(7.14 \%)$ \\
\hline $\begin{array}{l}\text { Inducible MLS в Resistance } \\
\text { (ERY-R,CL-S, positive D-test) }\end{array}$ & $13(12 \%)$ & $10(23.80 \%)$ \\
\hline $\begin{array}{l}\text { MS phenotype } \\
\text { (ERY-R,CL-S, negative D-test ) }\end{array}$ & $\begin{array}{l}33 \\
(30.55 \%)\end{array}$ & $14(33.33 \%)$ \\
\hline Total & $\mathbf{1 0 8}$ & $\mathbf{4 2}$ \\
\hline
\end{tabular}

ERY- Erythromycin, CL- Clindamycin, S-sensitive, R-resistent,

Table.2 Inducible clindamycin resistance in MRSA

\begin{tabular}{|c|c|}
\hline Authors & $\begin{array}{c}\text { Inducible clindamycin resistance in } \\
\text { MRSA (Percentage) }\end{array}$ \\
\hline Yilmaz et $a l^{8}$ & $24.40 \%$ \\
\hline${\text { Gadepalli } \text { et } a l .^{2}}^{2}$ & $30 \%$ \\
\hline Ajantha GS et al ${ }^{9}$ & $74 \%$ \\
\hline Rahabar M et al. ${ }^{10}$ & $22.60 \%$ \\
\hline Present study & $23.80 \%$ \\
\hline
\end{tabular}

Fig.1 Inducible clindamycin resistance

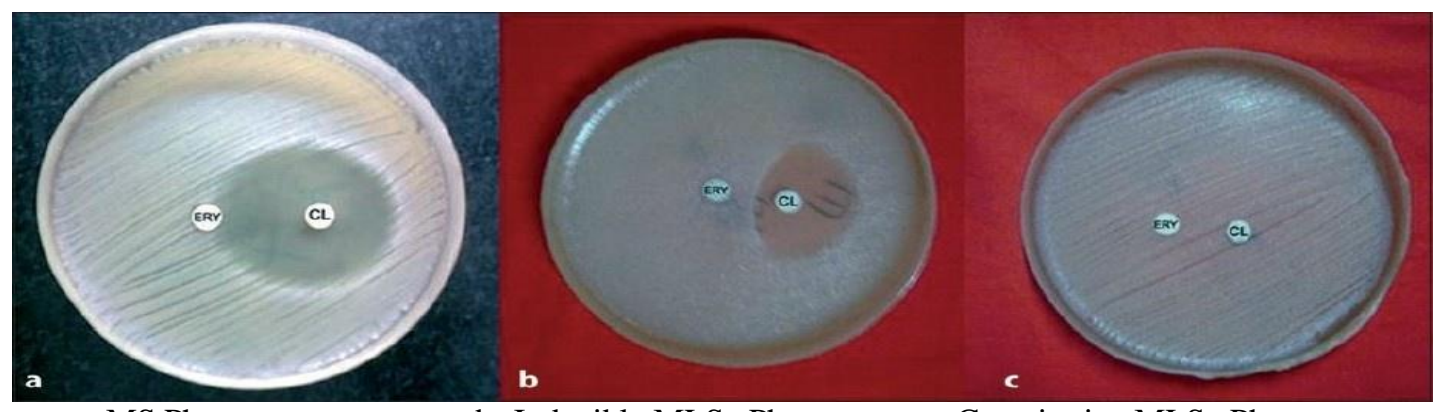

a- MS Phenotype

b- Inducible $\mathrm{MLS}_{\mathrm{B}}$ Phenotype c-Constitutive $\mathrm{MLS}_{\mathrm{B}}$ Phenotype

These observations suggest that if D-test had not been performed, nearly one fourth of the erythromycin resistant isolates would have been misidentified as clindamycin sensitive and resulting in therapeutic failure. Various authors have reported inducible clindamycin 
resistance ranging from $22.60 \%$ to $74 \%$ as shown in Table-2.

In conclusion, out of $108 \mathrm{~S}$. aureus isolates $50(32.4 \%)$ were erythromycin resistant isolates and $42(\%)$ isolates were found to be cefoxitin resistant (MRSA), Out of 42 MRSA, 27 were found to be erythromycin resistant. Incidence of Inducible clindamycin resistance was $12 \%$ observed in all S.aureus and $23.80 \%$ in MRSA isolates. Sensitivity to clindamycin can be judged after performing D test on the erythromycin resistant isolates.

\section{References}

1. Dowling HF. The newer penicillins. Clinic Pharmacol Ther 1961;2:572-80.

2. Fiebelkorn KR, Crawford SA, McElmeel ML, Jorgensen JH. Practical disc diffusion method for detection of inducible clindamycin resistance in Staphylococcus aureus and coagulase negative Staphylococci. J Clin Microbiol 2003;41:4740-4.

3. Gadepalli R, Dhawan B, Mohanty S, Kapil A, Das BK, Chaudhry R. Inducible clindamycin resistance in clinical isolates of Staphylococcus aureus. Indian J Med Res 2006; 123:571-3.

4. Steward CD, Raney PM, Morrell AK, Williams PP, McDougal LK, Jevitt L. Testing for induction of clindamycin resistance in erythromycin resistant isolates of Staphylococcus aureus. J Clin Microbiol 2005;43:1716-21.
5. Roberts MC, J Sutcliffe, P Courı , LB Jensen, J Rood, H pala. Nomenclature for macrolidelincosamide-streptograminB resistance determinants. Antimicrob Agents Chemother 1999;43:2823-30

6. Jorgensen JH, Crawford SA, McElmeel ML, Fiebelkorn KR. Detection of Inducible clindamycin resistance of Staphylococci in conjunction with performance of automated broth susceptibility testing. J Clin Microbiol 2004; 42:1800-2.

7. Clinical Laboratory Standards Institute. Performance standard for antimicrobial susceptibility testing: seventeenth informational supplement M100- S17, Vol 27 No 1.Clinical Laboratory Standards Institute, Wayne, PA, USA. 2007.

8. Yilmaz G, Aydin K, Iskender S, Caylan R, Koksal I. Detection and prevalence of inducible clindamycin resistance in staphylococci. J Med Microbiol 2007;56:342-5.

9. Ajantha GS, Kulkarni RD, Shetty J, Shubhada C, Jain P Phenotypic detection of inducible clindamycin resistance amongst Staphylococcus aureus isolates by using lower limit of recommended inter-disk distance. Indian J Pathol Microbiol 2008;51:3768.

10. Rahabar M, Hajia M. Inducible clindamycin resistance in Staphylococcus aureus a cross sectional report. Pak J Biol Sci 2007;10:189-92.

\section{How to cite this article:}

Sanyogita Jain, Atul Rukadhikar and Anil Kumar Jain. 2016. Inducible Clindamycin resistance in Staphylococcus aureus isolated from Clinical Samples at C. U. Shah Medical College and Hospital, Surendranagar, Gujarat, India. Int.J.Curr.Microbiol.App.Sci. 5(6): 875-879. doi: http://dx.doi.org/10.20546/ijcmas.2016.506.094 